\title{
An Ontology Roadmap for Crowdsourcing Innovation Intermediaries
}

\author{
Cândida Silva ${ }^{1}$ and Isabel Ramos ${ }^{2}$ \\ ${ }^{1}$ School of Management and Industrial Studies, Polytechnic Institute of Oporto, Vila do Conde, Portugal \\ ${ }^{2}$ Information Systems Department, School of Engineering, University of Minho, Guimarães, Portugal \\ Center Algoritmi, University of Minho \\ candidasilva@eu.ipp.pt,iramos@dsi.uminho.pt
}

Keywords: Ontology Building Methodologies, Crowdsourcing Innovation, Innovation Ontology, Ontology Enterprise.

Abstract: Ontologies have proliferated in the last years, essentially justified by the need of achieving a consensus in the multiple representations of reality inside computers, and therefore the accomplishment of interoperability between machines and systems. Ontologies provide an explicit conceptualization that describes the semantics of the data. Crowdsourcing innovation intermediaries are organizations that mediate the communication and relationship between companies that aspire to solve some problem or to take advantage of any business opportunity with a crowd that is prone to give ideas based on their knowledge, experience and wisdom, taking advantage of web 2.0 tools. Various ontologies have emerged, but at the best of our knowledge, there isn't any ontology that represents the entire process of intermediation of crowdsourcing innovation. In this paper we present an ontology roadmap for developing crowdsourcing innovation ontology of the intermediation process. Over the years, several authors have proposed some distinct methodologies, by different proposals of combining practices, activities, languages, according to the project they were involved in. We start making a literature review on ontology building, and analyse and compare ontologies that propose the development from scratch with the ones that propose reusing other ontologies. We also review enterprise and innovation ontologies known in literature. Finally, are presented the criteria for selecting the methodology and the roadmap for building crowdsourcing innovation intermediary ontology.

\section{INTRODUCTION}

Ontologies have proliferated in the last years, mostly in Computer Science and Information Systems areas. This is essentially justified by the need of achieving a consensus in the multiple representations of reality inside computers, and therefore the accomplishment of interoperability between machines and systems (Hepp, 2007).

Open innovation is a timely topic in innovation management. Its basic premise is open up the innovation process. The innovation process, in general sense, may be seen as the process of designing, developing and commercializing a novel product or service to improve the value added of a company.

This paradigm proposes the use of external and internal ideas, and internal and external paths to market, as means to reach advances in technology used by companies (Chesbrough, 2006).

The World Wide Web, the open source movement and the development of Web 2.0 tools facilitates this kind of contributions, opening space to the emergence of crowdsourcing innovation initiatives.

Jeff Howe and Mark Robinson introduced the term crowdsourcing, in an article in Wired Magazine (Howe, 2006), as a way of using the Web 2.0 tools to generate new ideas through the heterogeneous knowledge available in the global network of individuals highly qualified and with easy access to information and technology. Although, this concept has been used quite a time, the creation of the Wikipedia and of many examples of free software, like Linux, are examples of crowdsourcing activity. Crowdsourcing is a form of outsourcing not directed to other companies but to the crowd by means of an open call mostly through an Internet platform. Basically, the process is trying to solve a company problem by an open call in the network. The company posts a problem and a vast amount of individuals offers the solution for evaluation. The winning idea is awarded in some way and the 
company develops the idea. The crowd can be defined as a large set of anonymous and heterogeneous individuals, which may be composed of scientists and experts in various fields, but also of novices (Howe, 2008; Surowiecki, 2005).

A crowdsourcing innovation intermediary is an organization that mediates the communication and relationship between the seekers - companies that aspire to solve some problem or to take advantage of any business opportunity - with a crowd that is prone to give ideas based on their knowledge, experience and wisdom (Ramos et al., 2009).

For crowdsourcing innovation intermediary the crowd is composed by groups of specialists in different areas, such as individual researchers, research team, labs, post-graduate students and highly qualified individuals.

This paper makes a literature review on ontology building, and analyze and compare ontologies that propose the development from scratch with the ones that propose reusing other ontologies. It also review enterprise and innovation ontologies known in literature. Finally, are presented the criteria for selecting the methodology and the roadmap for building crowdsourcing innovation intermediary ontology.

To achieve this objectives we defined the following main questions, which guided the literature review: (i) What are the main concepts guiding ontologies building?; (ii) What are the existing ontologies about business and innovation?; (iii) Which methodologies should be considered to build an ontology?

To answer these questions, we started conducting an exhaustive bibliography review of the authors most relevant to the scientific area, identifying curriculum authors, books, book chapters, papers presented at conferences and published articles in scientific journals. This literature review was conducted by Scopus, Google Scholar, ISI Web of Knowledge. The documents were collected through the UM catalog, b-on; RCAAP, IEEExplore, Colcat.

Then, based on this extensive bibliography, we proceeded to the identification of the most relevant papers, gathering all those whose title refers to the following combination of words: "ontologies", "ontology development"; "ontology building"; "innovation ontology"; "enterprise ontology"; and "ontology methodologies".

This paper is organized as follows. In section 2 , is made a literature revision of ontology concepts such as its definition and features, classification of ontologies by different authors, application areas, and enterprise and innovation ontologies. Following, in section 3, we review literature on ontology methodologies. Finally, the conclusions of this work are presented and the roadmap for building a crowdsourcing innovation intermediary ontology.

\section{STAT OF ART ON ONTOLOGIES}

There are several definitions of the concept of ontology from where can be assemble that it has an informal and formal notion associated to it. Gruber (1995) definition clearly shows these - "An ontology is a formal, explicit specification of a standard conceptualization".

An ontology is a conceptualization of world view with respect to a given domain. This world view is conceived by a framework as a set of concept definitions and their interrelationships, that may be implicit, existing only in someone's head or tool, or explicit which includes a vocabulary of terms and a specification of their meanings.

The specification of that world view by means of a formal and declarative representation, with semantic interconnections, and some rules of inference and logic, will perform the formal ontology. The formal representation will facilitate the interoperability between heterogeneous machines and systems.

Ontologies have been developed with the promise of providing knowledge sharing and reuse between people and systems, by building a conceptual framework of a given knowledge domain to be represented. This framework will be formalized through a specific ontology language which will clearly express a controlled vocabulary and taxonomy, as represented in Figure 1.

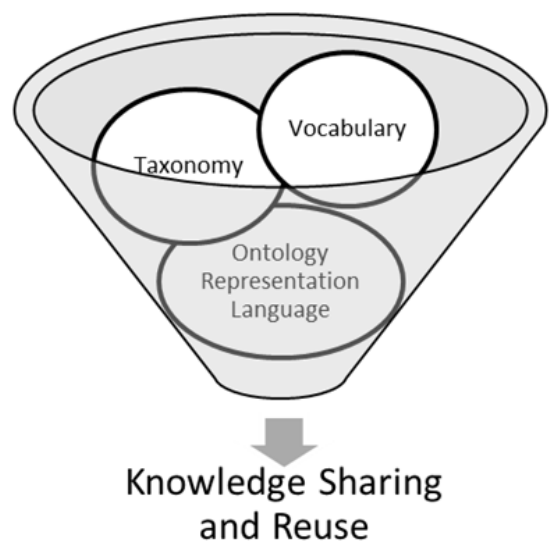

Figure 1: Ontology building features. 
The vocabulary is a list of terms or classes of objects, respective definitions and relationships between each other, provided by logical statements. They also specify rules for combining the terms and their relations to define extensions to the vocabulary.

The taxonomy or concept hierarchy is a hierarchical classification or categorization of entities in the domain of an ontology. The taxonomy should be in a machine-readable and machineprocessable form in order to permit interoperability.

The full specification of an ontology domain establishes a conceptual framework, composed by the vocabulary and the taxonomy, for discussion, analysis, and information retrieval in a domain.

Ontology development requires an effective ontological analysis of the content the world view domain that it intends to represent. This analysis will reveal the terms and concepts of the domain knowledge, their relations, organization and hierarchy. Thus, they clarify the structure of domain knowledge, so, it can be called a content theory (Gasevic et al., 2006, p.53).

As the objective of ontologies is to facilitate knowledge sharing and reuse between various agents, regardless of whether they are human or machines, then it can be said that ontologies are a prerequisite and a result of a consensual point of view on the world. It is a prerequisite for consensus because to have knowledge sharing agents must agree on their interpretation of a domain of the world. And it is a result of consensus because the model of meanings was built as result of a process of agreement between agents on a certain model of the world and its interpretations. Therefore, it is an essential requirement that any ontology can progress over the time (Fensel, 2004).

Briefly, an ontology provides an explicit conceptualization that describes the semantics of the data. As Fensel (2004) stated "ontology research is database research for the 21 st century where data need to be shared and not always fit into a simple table".

\subsection{Type of Ontologies}

Over the years, researchers of this body of knowledge, tried to clarify, classify and typify the concept of ontology, in terms of its definition, components, and application areas. Table 1 present a summary of, what we considered being, the most relevant contributions.

Analyzing these table and the different views on the classification of ontologies, we can organize them in different types by the subject or issue of conceptualization, and them, each of this type can have different degrees of formality, purpose or objective, and components.

Table 1: Ontologies' classification by researcher's perspectives.

\begin{tabular}{|c|c|}
\hline Author & Classification/Dimension \\
\hline Guarino (1995) & $\begin{array}{l}\text { Informal conceptual system } \\
\text { Formal semantic account } \\
\text { Representation of a conceptual system } \\
\text { with a logical theory } \\
\text { Vocabulary used by a logical theory } \\
\text { Meta-level specification of a logical } \\
\text { theory }\end{array}$ \\
\hline $\begin{array}{l}\text { Mizoguchi et } \\
\text { al. (1995) }\end{array}$ & $\begin{array}{l}\text { Content theory: } \\
\text { - Object ontology } \\
\text { - Activity ontology } \\
\text { - Field ontology } \\
\text { Task ontology } \\
\text { General or common-sense ontology }\end{array}$ \\
\hline $\begin{array}{l}\text { Uschold \& } \\
\text { Gruninger } \\
\text { (1996) }\end{array}$ & $\begin{array}{l}\text { Formality } \\
\text { - Informal, semi-formal, formal } \\
\text { Purpose } \\
\text { - Communication between humans } \\
\text { - Inter-operability among systems } \\
\text { - Systems engineering benefits } \\
\text { Subject matter } \\
\text { - Domain ontology } \\
\text { - Task/method/problem solving } \\
\text { ontology } \\
\text { - Representational/meta ontology }\end{array}$ \\
\hline $\begin{array}{l}\text { van Heijst et } \\
\text { al. (1997) }\end{array}$ & $\begin{array}{l}\text { Amount and structure of the } \\
\text { conceptualization } \\
\text { - Terminological ontology } \\
\text { - Information ontology } \\
\text { - Knowledge modelling ontology } \\
\text { Subject of conceptualization } \\
\text { - Application ontology } \\
\text { - Domain ontology } \\
\text { - Generic ontology } \\
\text { - Representation ontology }\end{array}$ \\
\hline Guarino (1998) & $\begin{array}{l}\text { Domain ontology } \\
\text { Meta-data ontology } \\
\text { General or common-sense ontology } \\
\text { Representational ontology } \\
\text { Method and task ontology }\end{array}$ \\
\hline $\begin{array}{c}\text { Lassila \& } \\
\text { McGuinness } \\
\text { (2001) }\end{array}$ & $\begin{array}{l}\text { Controlled vocabulary } \\
\text { Glossary } \\
\text { Thesaurus } \\
\text { Informal is-a hierarchy } \\
\text { Formal is-a hierarchy } \\
\text { Formal instances } \\
\text { Frames } \\
\text { Value restrictions } \\
\text { General logical constraints }\end{array}$ \\
\hline $\begin{array}{c}\text { Benjamins \& } \\
\text { Gómez-Pérez } \\
\text { (n.d.) }\end{array}$ & $\begin{array}{l}\text { Reusability } \\
\text { - Content ontologies: task, domain, } \\
\text { representation } \\
\text { - Issue of the conceptualization: } \\
\text { application, generic, representation, } \\
\text { domain }\end{array}$ \\
\hline
\end{tabular}


Table 1: Ontologies' classification by researcher's perspectives. (cont.)

\begin{tabular}{|l|l|}
\hline Author & \multicolumn{1}{|c|}{ Classification/Dimension } \\
\hline $\begin{array}{c}\text { A. Bullinger } \\
\text { (2008) }\end{array}$ & Subject matter \\
& - Application \\
& - Task \\
& - Domain \\
& - General \\
& - Representation \\
& Formality \\
& - Informal notation \\
& - Semi-informal/semi-formal notation \\
& - Formal notation \\
& Expressiveness \\
& - Taxonomy \\
& - Theasaurus \\
& - Topic map \\
& - Lightweight vs heavyweight \\
& ontology \\
\hline
\end{tabular}

So it seems some consensus that the types of ontologies, by subject or content matter are:

- Domain or content ontology - represents the knowledge valid for a given type of domain (e.g. enterprise, medical, electronic, mechanic).

- Meta-data ontology - provide a vocabulary for describing informational content (e.g. Dublin core describes on-line information sources).

- General or common-sense ontology provides basic notions and concepts about describing general knowledge about the world and so they are valid across several domains (e.g. time, space, state, event).

- Representational/frame ontology - ontologies that provide representational entities without stating what particular domain it represents. Do not commit to any particular domain.

- Task/method/problem solving ontology provide terms specific for particular tasks and problem-solving methods. It defines primitives by which the problem solving context can be described and domain knowledge can be put into the problem solving context.

\subsection{Application Areas}

Fensel (2004), in his book, classifies the main broad areas where ontologies are of interesting application: knowledge management, web commerce, electronic business and enterprise application integration. Gasevic et al. (2006) identified some high-level activities where the utilization of ontology technology applies perfectly, which are tasks that fall, somehow, in all these application areas. After all, those are the usual task for having knowledge share and reusability:

- Collaboration - ontologies provide a unique consensual knowledge framework that can be used as a common, shared reference to communicate and work with.

- Interoperation - ontologies enable information conversation, transfer and integration from different and heterogeneous sources. However, to permit automatic integration it is needed that all the sources recognize the same ontology.

- Education - ontologies can be a reliable and objective source of information to those who want to learn more about a specific domain, since it is expected that they result of a wide consensus of the structure of the knowledge domain they represent. So, they are also a good publication medium and source of reference.

- Modeling - the structure and hierarchy established in the ontology will represent important reusable building blocks, which many specific applications should include as predeveloped knowledge modules.

- E-commerce - Since ontologies enable interoperability between machines and systems, e-commerce can be considered an application domain for ontologies. They can be fully used in all the e-commerce tasks.

- Search engines - concepts and taxonomies from ontologies can be used to support structures, comparative, and customized searches.

\subsection{Enterprise Ontologies}

Enterprise ontologies are usually created to define and structure knowledge in business universe about the processes, activities, organization and strategies.

The first enterprise ontology (EO) project was developed at the University of Edinburg with the aim of promoting the common understanding between people across enterprises, as well as to serve as a communication medium between people and applications, and between different applications (Uschold et al., 1998). Its major role is to act as a communication medium, ensuring effective interchange of information and knowledge between different users, tasks and systems.

This implies that besides technical interoperability it is needed a semantic and 
pragmatic interoperability between applications and users (Leppänen, 2007).

The main intended uses for EO, identified by Uschold et al. (1998), were:

- "enhance communication between humans, for the benefit of integration;

- serve as stable basis for understanding and specifying the requirements for end-user applications using the Tool Set which in turn leads to more flexibility in an organization;

- to achieve interoperability among disparate tools in an enterprise modeling environment using the EO as an interchange format."

To develop the EO, the authors used brainstorming technique to identify the maximum of potential terms that are relevant to enterprises. The list of terms and phrases harvested were then grouped by similar areas and established priorities to include the terms in the ontology. The resultant list of terms was categorized to identify the core and specific terms of each area and define it. The core concepts define the Meta-Ontology of EO.

The EO establish the following basic core terms in a Meta-Ontology: Entity, Relationship, Role, Attribute, State of Affairs, Achieve, Actor, Actor Role, and Potential Actor. The specific terms defined by EO were grouped into five working areas: Activity, Organization, Strategy, Marketing, and Time, as presented in Table 2.

First, the EO was defined in an informal way, establishing its concepts in plain English and later, in the formalization phase, the terms were encoded into Ontolingua language. The Ontolingua has already adequate primitives to cover what was required to represent Enterprise Meta-Ontology, namely: objects, relations, and functions. Thus, it was evaluated the concepts that already are defined by Ontolingua and imported to EO. The formal Enterprise Meta-ontology become: Actor, Function, Set, Thing, Potential Actor, Relation and State of Affairs.

This ontology has been successfully used as a mean to achieve inter-operation through a common terminology used for specifying tasks, capabilities, and agents; and to enhance communication between humans by using terms in a consistent way.

Some of the failures of this project were the difficulty to use formal definitions and to have automatic interpretations; the lack of an interchange format to other ontologies; the fact of being too generic; and missing a graphic context for browsing the list of terms.
Table 2: List of terms defined by Enterprise Ontology by working area (Uschold et al., 1998).

\begin{tabular}{|c|c|}
\hline Activity & $\begin{array}{l}\text { Activity Specification, Execute, } \\
\text { Executed Activity Specification, T- } \\
\text { Begin, T-End, Pre-Conditions, Effect, } \\
\text { Doer, Sub-Activity, Authority, } \\
\text { Activity Owner, Event, Plan, Sub- } \\
\text { Plan, Planning, Process Specification, } \\
\text { Capability, Skill, Resource, Resource } \\
\text { Allocation, Resource Substitute. }\end{array}$ \\
\hline Organization & $\begin{array}{l}\text { Person, Machine, Corporation, } \\
\text { Partnership, Partner, Legal Entity, } \\
\text { Organizational Unit, Manage, } \\
\text { Delegate, Management Link, Legal } \\
\text { Ownership, Non-Legal Ownership, } \\
\text { Ownership, Owner, Asset, } \\
\text { Stakeholder, Employment Contract, } \\
\text { Share, Share Holder. }\end{array}$ \\
\hline Marketing & $\begin{array}{l}\text { Purpose, Hold Purpose, Intended } \\
\text { Purpose, Strategic Purpose, } \\
\text { Objective, vision, Mission, Goal, } \\
\text { Help Achieve, Strategy, Strategic } \\
\text { Planning, Strategic Action, Decision, } \\
\text { Assumption, Critical Assumption, } \\
\text { Non-Critical Assumption, Influence } \\
\text { Factor, Critical Influence Factor, } \\
\text { Non-Critical Influence Factor, Critical } \\
\text { Success Factor, Risk. }\end{array}$ \\
\hline Strategy & $\begin{array}{l}\text { Sale, Potential Sale, For Sale, Sale } \\
\text { Offer, Vendor, Actual Customer, } \\
\text { Potential Customer, Customer, } \\
\text { Reseller, Product, Asking Price, Sale } \\
\text { Price, Market, Segmentation } \\
\text { Variable, Market Segment, Market } \\
\text { Research, Brand Image, Feature, } \\
\text { Need, Market Need, Promotion, } \\
\text { Competitor. }\end{array}$ \\
\hline Time & $\begin{array}{l}\text { Time Line, Time Interval, Time } \\
\text { Point. }\end{array}$ \\
\hline
\end{tabular}

The TOVE (TOronto Virtual Enterprise) project, developed in the University of Toronto, came out as an enterprise ontology that solves the problems presented above.

TOVE aims to create a generic, reusable enterprise model for a company. This model must (1) provide a shared terminology; (2) defines the meanings of each term in a precise and unambiguous manner; (3) implements semantics in a set of axioms, and (4) provide a graphical context for depicting terms or concepts (Fox \& Gruninger, 1998).

TOVE was implemented with two formal languages: $\mathrm{C}++$ for the static part and Prolog the axioms. The ontology implementation started with a generic ontology for enterprises, but additionally, it has been created more specific ontologies covering enterprise subareas, like, business and project 
process, organization, logistics, transport ant store, scheduling, and information resources (GómezPérez et al. 2004).

\subsection{Innovation Ontologies}

Ning et al. (2006) presented a system architecture that combines ontology, inference and mediation technologies to create a semantic web of innovation knowledge, which they called Semantic Innovation Management (SIM). The framework of the system was based on metadata harvesting and RDF access technologies.

Bullinger (2008), in her $\mathrm{PhD}$ thesis, develop OntoGate, ontology to manage idea assessment and selection of the innovation process.

Also Riedl et al. (2009) proposed an ontology to represent ideas of the innovation management process. It defines the core idea concept that is enriched by other concepts like collaborative idea development, including rating, discussing, tagging, and grouping ideas.

They classified the ontology as an application ontology because it provides a description of a technical architecture to represent complex ideas evaluations along various concepts. It offers a common language to idea storage and exchange for the purpose of achieving interoperability across innovation tools.

The ontology was built following the methodology proposed by Noy \& McGuinness (2001), and reused other existing ontologies, as suggested.

The Table 3 presents the main classes of idea ontology, and the source of each class. When the class is new, the source ontology will be Idea Ontology. It was also reused the Enterprise Ontology to model the descriptive attributes of an idea.

Table 3: Idea Ontology terms and related source ontology.

\begin{tabular}{|c|l|}
\hline Class & \multicolumn{1}{|c|}{ Source } \\
\hline CoreIdea & Idea Ontology \\
\hline Document & Friend of a Friend (FOAF) \\
\hline Item & $\begin{array}{l}\text { Semantically-Interlinked Online } \\
\text { Communities (SIOC) }\end{array}$ \\
\hline Resource & Resource Description Framework (RDF) \\
\hline Origin & Idea Ontology \\
\hline Rating & Rating Ontology \\
\hline Person & FOAF \\
\hline Tagging & Tag ontology \\
\hline Concept & $\begin{array}{l}\text { Simple Knowledge Organization } \\
\text { Ontology (SKOS) }\end{array}$ \\
\hline
\end{tabular}

\section{ONTOLOGY BUILDING METHODOLOGIES}

Ontology methodologies comprises a set of established principles, processes, practices, and activities used to design, formalize, implement, evaluate, and deploy ontologies, for which uses some development tools. These development tools include ontology representation languages, graphical ontology development environment, and ontologylearning tools.

To develop an ontology it must be first answered questions like: what is the scope of the ontology? Who is interested in it? Who will use and maintain it? Which methods and methodologies can be used to build ontologies? Which activities are performed? Which tools gives support to the ontology development process? Which ontology language can be used to implement ontologies? Which methodology, tool and language should be used to develop and to implement an ontology for crowdsourcing innovation intermediaries?

Noy \& McGuinness (2001) gave some basic advices in seven steps for the process building of your first ontology, and that helps to answer these questions:

1. Determine the domain and scope of the ontology: This step should help to define the knowledge domain covered, to limit the scope of the model, and the users and maintainer of the ontology.

2. Consider reusing existing ontologies: Before starting to create an ontology from scratch, it is worth to check if there exist any ontology that can be refine or extend that cover our particular domain or task. Reusing ontologies specially considered if our system needs to interact with other applications that have already committed to particular ontologies or controlled vocabularies, in order to reduce the translation effort.

3. Enumerate important terms: Ontology development should start by listing all the terms we thing important or like to explain to user, and describe them briefly.

4. Define the classes and their hierarchy: This step and the following are taken by turns.

5. Define the properties of the classes: Expresses the internal structure of concepts by explicating their extrinsic properties (name, duration, and use), intrinsic properties (weight, colour, etc), parts, and relations to other classes and individuals in those classes.

6. Define the characteristics classes' properties: Defining things like attributes type, domain and 
range allowed values, cardinality, and other features.

7. Create instances: Creating individual instance of classes in the hierarchy, filling in the attributes values.

Over the years, several authors have proposed some distinct methodologies, by different proposals of combining practices, activities, languages, etc, according to the project they were involved in. Fernández-Pérez \& Gómez-Pérez (2002) and Corcho et al. (2003) described some of these methodologies and compared their degree of maturity. They selected, at the time, the best-known approaches for both building from scratch and reusing ontologies, which are summarize in Appendix.

\section{CONCLUSIONS}

The ontologies are presented as a conceptual model for the systematization and formalization of consensual knowledge in a field of knowledge. This conceptualization is rendered concrete with the definition of terms and concepts from the domain of knowledge in analysis, their relationships, organization and hierarchy, and allows the sharing and reuse by different people and systems of such knowledge (Corcho et al., 2003; Corcho et al., 2002; Fensel et al., 2000; Hepp, 2007; Smirnov et al., 2005; Tang et al., 2006).

Some of the difficulties of sharing knowledge and reusing ontologies are (Gasevic et al. 2006): the existence of several different languages to representing ontologies, and tools may not support the language used to develop the ontology; there are many diverse ontologies that have been developed to describe the same topic or domain, resulting of using different competing methodologies and working groups. To build an ontology by combining some of them may require a lot of manual adjustments because of deep differences between them, and the resulting ontology may still inadequate to fulfill all the requirements; and difficulties on ontology maintenance, since all parts of knowledge evolve over time.

Various ontologies have emerged, particularly in the areas of business and enterprise. Ning et al. (2006), Bullinger (2008), and more recently Riedl et al. (2009b), proposed ontologies for the process of innovation management, but they represent only the component relating to the process of generating ideas. Not the best of our knowledge, the existence of any ontology that represents the entire process of creating an intermediate value of crowdsourcing innovation. Thus, an ontology of crowdsourcing innovation intermediaries will be an instrument to understand this phenomenon and thus will also be a facilitator for the emergence of such intermediaries.

The roadmap for building this ontology comprises two main phases: in the first phase is being conducted an empirical study with innovation intermediaries that rely on innovation and crowdsourcing to develop some of their tasks or solve problems. The result of this study will be a model of knowledge for innovation intermediaries with crowdsourcing. This model of knowledge will be the basis for the ontology development. The second stage will involve the development of the ontology itself. First will be developed a domain or content ontology that represent the entire taxonomy of concepts and their hierarchy of the underlying knowledge model of an innovation intermediary with crowdsourcing. After it will be developed a meta-data ontology to provide a descriptive vocabulary of this knowledge area. With these two artefacts we intend to contribute to the standardization of concepts in this area of knowledge and to enhance the emergence of such intermediaries.

The ontology development project will be performed using the NeOn methodology (cf. table in appendix), as this is a very complete methodology, which provides guidance in all phases of project development, allowing the use of ontological and not ontological resources, collaborative development, and evolution and maintenance of the ontology network. Also, the use of the Web Ontology Language, which is a suitable language for developing web ontologies, widely used, and also it provides a tool to support the development of ontology, but without being mandatory the use of this tool.

\section{ACKNOWLEDGEMENTS}

This work has been supported by FCT - Fundação para a Ciência e Tecnologia within the Project Scope: PEst-OE/EEI/UI0319/2014.

\section{REFERENCES}

Benjamins, V.R. \& Gómez-Pérez, A., n.d. KnowledgeSystem Technology: Ontologies and Problem-Solving 
Methods. Department of Socia Science Informatics, University of Amsterdam.

Bernaras, A., Laresgoiti, I., \& Correa, J., 1996. Building and Reusing Ontologies for Electrical Network Applications. In Proceedings of the European Conference on Artificial Intelligence (ECAI96). Budapeste, Hungary.

Bullinger, A., 2008. Innovation and Ontologies: Structuring the Early Stages of Innovation Management, Springer.

Chesbrough, H.W., 2006. Open Innovation: Researching a New Paradigm Henry Chesbrought,Wim Vanhaverbeke and Joel West, Eds., Oxford University Press.

Corcho, Ó. et al., 2002. WebODE: An Integrated Workbench for Ontology Representation, Reasoning, and Exchange. In Knowledge Engineering and Knowledge Management: Ontologies and the Semantic Web. pp. 295-310.

Corcho, O., Fernández-López, M. \& Gómez-Pérez, A., 2003. Methodologies, tools and languages for building ontologies. Where is their meeting point? Data \& Knowledge Engineering, 46(1), pp.41-64.

Fensel, D. et al., 2000. On-To-Knowledge: Ontologybased Tools for Knowledge Management. In Proceedings of the eBusiness and eWork 2000 (EMMSEC 2000) Conference. eBusiness and eWork 2000 (EMMSEC 2000) Conference. Madrid, Spain.

Fensel, D., 2004. Ontologies: A Silves Bullet for Knowledge Management and Electronic Commerce 2 Ed., Springer-Verlag Berling Heidelberg.

Fernández-Pérez, M. \& Gómez-Pérez, A., 2002. Overview and Analysis of Methodologies for Building Ontologies. The Knowledge Engineering Review, 17(02), pp.129-156.

Fox, M.S. \& Gruninger, M., 1998. Enterprise Modeling. AI Magazine, 19(3), pp.109-121.

Gasevic, D., Djuric, D. \& Devedzic, V., 2006. Model Driven Architecture and Ontology Development, Springer-Verlag Berling Heidelberg.

Gómez-Pérez, A., Fernández-López, M. \& Corcho, O., 2004. Ontological engineering: with examples from the areas of knowledge management, e-commerce and the Semantic Web, Springer.

Gómez-Pérez, A., \& Suárez-Figueroa, M. C., 2008. NeOn Methodology: Scenarios for Building Networks of Ontologies. In Proceedings of the 16th International Conference on Knowledge Engineering and Knowledge Management Knowledge Patterns (EKAW 2008).

Gruber, T.R., 1995. Toward principles for the design of ontologies used for knowledge sharing? International Journal of Human-Computer Studies, 43(5-6), pp.907-928.

Grüninger, M., \& Fox, M. S., 1995. Methodology for the Design and Evaluation of Ontologies. Presented at the Workshop on Basic Ontological Issues in Knowledge Sharing, IJCAI-95, Montreal.

Guarino, N., 1998. Formal ontology in Information
Systems. In Proceedings of FOIS'98. FOIS'98. Trento, Italy.

Guarino, N., 1995. Formal ontology, conceptual analysis and knowedge representation. International Journal of Human-Computer Studies, 43(5/6), pp.625-640.

Van Heijst, G., Schreiber, A.T. \& Wielinga, B.J., 1997. Using explicit ontologies in KBS development. International Journal of Human-Computer Studies, 46(2-3), pp.183-292.

Hepp, M., 2007. Ontologies: State of Art, Business Potential, and Grand Challenges. In Ontology Management: Semantic Web, Semantic Web Services, and Business Applications. Springer, pp. 3-22.

Howe, J., 2008. Crowdsourcing: How the Power of the Crowd is Driving the Future of Business, Crown Business.

Howe, J., 2006. The Rise of Crowdsourcing. Wired Magazine, 14.06, pp.1-4.

Lassila, O. \& McGuinness, D., 2001. The Role of FrameBased Representation on the Semantic Web, Stanford: Knowledge Systems Laboratory.

Lenat, D. B., \& Guha, R. V., 1990. Building Large Knowledge-Based Systems: Representation and Inference in the Cyc Project. Addison-Wesley Pub (Sd).

Leppänen, M., 2007. A Context-Based Enterprise Ontology. In Business Information Systems. LNCS Lecture Notes in Computer Science. Springer Berlin / Heidelberg, pp. 273-286.

Mizoguchi, R., Vanwelkenhuysen, J. \& Ikeda, M., 1995. Task ontology for reuse of problem solving knowledge. In N. J. I. Mars, ed. Towards Very Large Knowledge Bases: Knowledge Building \& Knowledge Sharing. IOS Press.

Ning, K. et al., 2006. Semantic innovation management across the extended enterprise. International Journal of Industrial and Systems Engineering, 1(1-2), pp.109-128.

Noy, N.F. \& McGuinness, D.L., 2001. Ontology Development 101: A Guide to Creating Your First Ontology, Knowledge Systems Laboratory: Standford University.

Ramos, I. et al., 2009. An Action Research on Open Knowledge and Technology Transfer. In Information Systems - Creativity and Innovation in Small and Medium-Sized Enterprises. IFIP Advances in Information and Communication Technology. Information Systems - Creativity and Innovation in Small and Medium-Sized Enterprises. Guimarães, Portugal: Springer Boston, pp. 211-223.

Riedl, C. et al., 2009a. An Idea Ontology for Innovation Management. International Journal on Semantic Web and Information Systems, 5(4), pp.1-18.

Riedl, C. et al., 2009b. Managing Service Innovations with an Idea Ontology. In Proceedings of XIX International RESER Conference. XIX International RESER Conference: Public an Private Services in the New Global Economy. Budapeste, Hungary, pp. 876-892.

Smirnov, A. et al., 2005. Ontology-based knowledge 
repository support for healthgrids. Studies of technology and informatics, 112, pp.47-56.

Surowiecki, J., 2005. The wisdom of crowds, Anchor Books.

Swartout, B. et al., 1997. Toward Distributed Use of Large-Scale Ontologies. AAAI Symposium on Ontological Engineering.

Tang, L. et al., 2006. WISE: A Prototype for Ontology Driven Development of Web Information Systems. In Frontiers of $W W W$ Research and Development $A P W e b$ 2006. Lecture Notes in Computer Science. Springer Berlin / Heidelberg, pp. 1163-1167.
Uschold, M. et al., 1998. The Enterprise Ontology. The Knowledge Engineering Review, 13(01), pp.31-89.

Uschold, M. \& Gruninger, M., 1996. Ontologies: Principles, Methods and Applications. The Knowledge Engineering Review, 11(02), pp.93-136.

Uschold, M., \& King, M., 1995. Towards a Methodology for Building Ontologies. In Workshop on Basic Ontological Issues in Knowledge Sharing, held in conjunction with IJCAI-95.

\section{APPENDIX}

Table 4: Ontology building methodologies.

\begin{tabular}{|c|c|c|c|c|c|c|c|}
\hline & Aim & Method & Phases & Activities & Language & Tool & \begin{tabular}{|c|} 
Build \\
coope- \\
ration
\end{tabular} \\
\hline $\begin{array}{l}\text { Cyc KB - } \\
\text { Knowledge } \\
\text { Base } \\
\text { (Lenat \& } \\
\text { Guha, 1990) }\end{array}$ & $\begin{array}{l}\text { Capture a large } \\
\text { portion of what } \\
\text { people normally } \\
\text { considered } \\
\text { consensus } \\
\text { knowledge about } \\
\text { the world } \\
\end{array}$ & $\begin{array}{l}\text { From scratch: } \\
\text { bottom-up }\end{array}$ & $\begin{array}{l}\text { 1. Manual extraction of common } \\
\text { sense knowledge; } 2 \text {. } \\
\text { Codification: Computer aided } \\
\text { extraction of common sense } \\
\text { language; } 3 \text {. Computer managed } \\
\text { extraction of common sense } \\
\text { knowledge }\end{array}$ & $\begin{array}{l}\text { Implementation; } \\
\text { Knowledge } \\
\text { acquisition; } \\
\text { Documentation }\end{array}$ & $\begin{array}{l}\text { CycL, an augmentation } \\
\text { of first-order predicate } \\
\text { calculus, with extensions } \\
\text { to handle equality, } \\
\text { reasoning, skolemisation, } \\
\text { and some second-order } \\
\text { features } \\
\end{array}$ & & No \\
\hline $\begin{array}{l}\text { Uschold and } \\
\text { King } \\
\text { (Uschold \& } \\
\text { King, 1995) }\end{array}$ & $\begin{array}{l}\text { Enterprise } \\
\text { modeling } \\
\text { processes }\end{array}$ & $\begin{array}{l}\text { From scratch: } \\
\text { middle-out }\end{array}$ & $\begin{array}{l}\text { 1. Identify purpose; } 2 \text {. Building: } \\
\text { Capture; Coding; Integrating } \\
\text { 3. Evaluation; 4. Documentation }\end{array}$ & $\begin{array}{l}\text { Requirements; } \\
\text { Implementation; } \\
\text { Knowledge } \\
\text { acquisition; } \\
\text { Verification and } \\
\text { validation; } \\
\text { Documentation } \\
\end{array}$ & Ontolingua & $\begin{array}{l}\text { Onto- } \\
\text { lingua } \\
\text { Server }\end{array}$ & No \\
\hline $\begin{array}{l}\text { Grüninger and } \\
\text { Fox } \\
\text { (Grüninger \& } \\
\text { Fox, 1995) }\end{array}$ & $\begin{array}{l}\text { Business } \\
\text { processes and } \\
\text { activities } \\
\text { modeling; support } \\
\text { design-in-large } \\
\text { scale projects }\end{array}$ & From scratch & $\begin{array}{l}\text { 1. Capture of motivating } \\
\text { scenarios; } 2 \text {. Formulation of } \\
\text { informal competency questions; } \\
\text { 3. Specification of the } \\
\text { terminology of the ontology } \\
\text { within a formal language; } 4 \text {. } \\
\text { Formulation of formal } \\
\text { competency questions using the } \\
\text { terminology of the ontology; } 5 \text {. } \\
\text { Specification of axioms and } \\
\text { definitions for the terms in the } \\
\text { ontology within the formal } \\
\text { language; } 6 \text {. Establish conditions } \\
\text { for characterizing the } \\
\text { completeness of the ontology }\end{array}$ & $\begin{array}{l}\text { Requirements; } \\
\text { Design; } \\
\text { Implementation; } \\
\text { Knowledge } \\
\text { acquisition; } \\
\text { Verification and } \\
\text { validation; } \\
\text { Documentation }\end{array}$ & $\begin{array}{l}\text { KIF (Knowledge } \\
\text { Interchange Format), } \\
\text { first-order logic }\end{array}$ & & No \\
\hline $\begin{array}{l}\text { KACTUS } \\
\text { (Bernaras, } \\
\text { Laresgoiti, \& } \\
\text { Correa, 1996) }\end{array}$ & $\begin{array}{l}\text { Complex } \\
\text { technical systems } \\
\text { development }\end{array}$ & $\begin{array}{l}\text { From scratch: } \\
\text { up-down; } \\
\text { modifying } \\
\text { other existing } \\
\text { ontologies of } \\
\text { application } \\
\text { development } \\
\end{array}$ & $\begin{array}{l}\text { 1. Specification of the } \\
\text { application; } 2 \text {. Preliminary } \\
\text { design based on relevant top- } \\
\text { level ontological categories; } 3 \text {. } \\
\text { Ontology refinement and } \\
\text { structuring }\end{array}$ & $\begin{array}{l}\text { Requirements; } \\
\text { Design; } \\
\text { Implementation; } \\
\text { Maintenance }\end{array}$ & $\begin{array}{l}\text { CML (Chemical Markup } \\
\text { Language); Express; } \\
\text { Ontolingua }\end{array}$ & $\begin{array}{l}\text { KACT } \\
\text { US } \\
\text { toolkit }\end{array}$ & No \\
\hline $\begin{array}{l}\text { METHONTO } \\
\text { LOGY } \\
\text { (Fernández- } \\
\text { López, } \\
\text { Gómez-Pérez, } \\
\text { \& Juristo, } \\
\text { 1997) }\end{array}$ & $\begin{array}{l}\text { Support } \\
\text { application } \\
\text { development } \\
\text { process }\end{array}$ & Re-engineering & $\begin{array}{l}\text { 1. Project management activities } \\
\text { (Schedule; Control; Quality } \\
\text { assurance); 2. Development- } \\
\text { oriented activities (Specification; } \\
\text { Conceptualization; } \\
\text { Formalization; Implementation; } \\
\text { Maintenance); 3. Support } \\
\text { activities (Knowledge } \\
\text { acquisition; Integration; } \\
\text { Evaluation; Documentation; } \\
\text { Configuration management) }\end{array}$ & $\begin{array}{l}\text { Project monitoring } \\
\text { and control; } \\
\text { Requirements; } \\
\text { Design; } \\
\text { Implementation; } \\
\text { Maintenance; } \\
\text { Knowledge } \\
\text { acquisition; } \\
\text { Verification and } \\
\text { validation; } \\
\text { Ontology } \\
\text { configuration } \\
\text { management; } \\
\text { Documentation } \\
\end{array}$ & $\begin{array}{l}\text { OWL,DAML+OIL; } \\
\text { RDF; XML; OCML }\end{array}$ & $\begin{array}{l}\text { ODE } \\
\text { (Ontolo } \\
\text { gy } \\
\text { Design } \\
\text { Environ } \\
\text { ment) } \\
\text { and } \\
\text { WEB- } \\
\text { ODE }\end{array}$ & No \\
\hline
\end{tabular}


Table 4: Ontology building methodologies. (cont.)

\begin{tabular}{|c|c|c|c|c|c|c|c|}
\hline & Aim & Method & Phases & Activities & Language & Tool & $\begin{array}{l}\text { Build } \\
\text { coope- } \\
\text { ration }\end{array}$ \\
\hline $\begin{array}{l}\text { On-To- } \\
\text { Knowledge } \\
\text { (Fensel, Van } \\
\text { Harmelen, } \\
\text { Klein, \& } \\
\text { Akkermans, } \\
2000)\end{array}$ & $\begin{array}{l}\text { Knowledge } \\
\text { management of } \\
\text { heterogeneous } \\
\text { sources in the } \\
\text { internet }\end{array}$ & From scratch & $\begin{array}{l}\text { 1. Kick-off: requirements capture } \\
\text { and specification; } 2 \text {. Refinement; } \\
\text { 3. Evaluation; 4. Maintenance }\end{array}$ & \begin{tabular}{|l|} 
Project initiation; \\
Project monitoring \\
and control; \\
Ontology quality \\
management; \\
Concept \\
exploration; \\
Requirements; \\
Design; \\
Implementation; \\
Maintenance; \\
Knowledge \\
acquisition; \\
Verification and \\
validation; \\
Ontology \\
configuration \\
management; \\
Documentation \\
\end{tabular} & $\begin{array}{l}\text { OIL (Ontology-based } \\
\text { Inference Layer); XML; } \\
\text { RDF }\end{array}$ & $\begin{array}{l}\text { OntoEd } \\
\text { it }\end{array}$ & No \\
\hline $\begin{array}{l}\text { SENSUS } \\
\text { (Swartout et } \\
\text { al., 1997) }\end{array}$ & $\begin{array}{l}\text { Natural language } \\
\text { processing for } \\
\text { developing } \\
\text { machine } \\
\text { translators } \\
\end{array}$ & $\begin{array}{l}\text { From scratch: } \\
\text { up-down }\end{array}$ & $\begin{array}{l}\text { 1. Identify seed terms; } 2 \text {. Link } \\
\text { seed terms to SENSUS by hand; } \\
\text { 3. Include nodes on the path to } \\
\text { root; } 4 \text {. Add some complete sub- } \\
\text { trees }\end{array}$ & $\begin{array}{l}\text { Requirements; } \\
\text { Implementation }\end{array}$ & DL: LOOM & $\begin{array}{l}\text { Ontosa } \\
\text { urus }\end{array}$ & No \\
\hline $\begin{array}{l}(\mathrm{KA})^{2} \\
\text { (Knowledge } \\
\text { Annotation } \\
\text { Initiative of the } \\
\text { Knowledge } \\
\text { Acquisition } \\
\text { Community) }\end{array}$ & $\begin{array}{l}\text { To model the } \\
\text { knowledge } \\
\text { acquisition } \\
\text { community using } \\
\text { ontologies } \\
\text { developed in a } \\
\text { joint effort of } \\
\text { people at different } \\
\text { locations using } \\
\text { the same } \\
\text { templates and } \\
\text { language, by } \\
\text { annotating WWW } \\
\text { documents, in a } \\
\text { distributive } \\
\text { ontological } \\
\text { engineering } \\
\text { process } \\
\end{array}$ & From scratch & Implementation & Implementation & Frame Logic & $\begin{array}{l}\text { Ontobr } \\
\text { oker }\end{array}$ & Yes \\
\hline $\begin{array}{l}\text { NeOn } \\
\text { (Gómez-Pérez } \\
\text { \& Suárez- } \\
\text { Figueroa, } \\
\text { 2008) }\end{array}$ & $\begin{array}{l}\text { It provides } \\
\text { guidance for all } \\
\text { key aspects of the } \\
\text { ontology } \\
\text { engineering } \\
\text { process, that is, } \\
\text { collaborative } \\
\text { ontology } \\
\text { development, } \\
\text { reuse of } \\
\text { ontological and } \\
\text { non-ontological } \\
\text { resources, and the } \\
\text { evolution and } \\
\text { maintenance of } \\
\text { networked } \\
\text { ontologies, } \\
\text { through nine } \\
\text { scenarios. }\end{array}$ & Re-engineering & $\begin{array}{l}\text { 1. Initiation (Requirements } \\
\text { specification; Scheduling; } \\
\text { Evaluation); 2. Reuse (Non- } \\
\text { Ontological Resource (NOR) } \\
\text { Reuse; Search; Reuse; } \\
\text { Statements Reuse; Evaluation); } \\
\text { 3. Merging (Aligning; } \\
\text { Evaluation); 4. Re-engineering } \\
\text { (NOR Reengineering; } \\
\text { Modularization; Evaluation); } 5 . \\
\text { Design (Conceptualization; } \\
\text { Evolution; Localization; } \\
\text { Evaluation); 6. Implementation } \\
\text { (Evaluation; Maintenance; } \\
\text { Evaluation) }\end{array}$ & $\begin{array}{l}\text { Project monitoring } \\
\text { and control } \\
\text { Requirements } \\
\text { Design } \\
\text { Implementation } \\
\text { Maintenance } \\
\text { Knowledge } \\
\text { acquisition } \\
\text { Verification and } \\
\text { validation } \\
\text { Ontology } \\
\text { configuration } \\
\text { management } \\
\text { Documentation }\end{array}$ & $\begin{array}{l}\text { OWL (Web Ontology } \\
\text { Language) }\end{array}$ & $\begin{array}{l}\text { NTK - } \\
\text { NeOn } \\
\text { Toolkit }\end{array}$ & Yes \\
\hline
\end{tabular}

